\title{
Akut Koroner Sendromlu Hastalarda Kronik Total Oklüzyon Sıklığı ve Risk Faktörleriyle İlişkisi
}

\author{
Taner Sarak ${ }^{1 *}$, Muhammed Karadeniz ${ }^{1}$ \\ ${ }^{1}$ Kırıkkale Üniversitesi Tıp Fakültesi Kardiyoloji Kliniği, Kırıkkale, Türkiye \\ email: tansara@ttmail.com,drkaradeniz36@gmail.com \\ Orcid: 0000-0002-5538-502X \\ Orcid: 0000-0003-2432-0378 \\ *Sorumlu Yazar / Corresponding Author: Sorumlu Yazar: Taner Sarak \\ Gönderim Tarihi / Received: 06.02.2019 \\ Kabul Tarihi / Accepted: 08.08.2019 \\ DOI: $10.34087 /$ cbusbed.522987
}

\begin{abstract}
Amaç: Bu çalışma kliniğimizde akut koroner sendrom sebebiyle yatarak tedavi edilen hastalarda kronik total oklüzyon (KTO) sıklığı ve bunun kardiyovasküler risk faktörleriyle ilişkisini belirlemek amacıyla yapılmıştır.

Gereç ve yöntem: Çalışmaya Nisan 2015 - Eylül 2018 tarihleri arasında akut koroner sendrom sebebiyle koroner anjiyografik değerlendirmeye alınan hastalar dahil edildi. Koroner anjiyografik incelemelerde lezyon bölgesinde TIMI 0 akım olan hastalar KTO olarak kabul edildi. Risk faktörleri anamnez ve laboratuvar bulgularına göre tespit edildi.

Bulgular: Çalışmaya kriterlere uyan 904 hasta dahil edildi. İki yüz on dört hastada (\%23) KTO tespit edildi. KTO olan hastalarda ortalama yaş $(67 \pm 11,60 \pm 13, \mathrm{p}<0.001)$, hipertansiyon varlığ $(\% 54.7, \% 43.0, \mathrm{p}=0.004)$ ve diyabetes mellitus $(\% 41.1, \% 31.6, p=0.013)$ istatistiksel olarak daha yüksek saptand1, erkek cinsiyet $(\% 64, \% 73, p$ $=0.008)$, prematüre koroner arter hastalığı öyküsü $(\% 10.3, \% 19.9, \mathrm{p}=0.001)$ ve sigara kullanımı $(\% 28.0, \% 48.8, \mathrm{p}$ $<0.001)$ ise daha düşük saptand1.
\end{abstract}

Sonuç: Bu çalışmada akut koroner sendrom hastalarında KTO'su olan ve olmayan hasta grupları arasında risk faktörleri açısından anlamlı farklar olduğu tespit edildi Bildiğimiz kadarıyla, bu çalışma literatürdeki kronik total tıkanma ve kardiyovasküler risk faktörleri arasındaki ilişkiyi gösteren ilk çalışmadır.

Anahtar Kelimeler: Akut Koroner Sendrom, Kronik Total Oklüzyon, Kardiyovasküler Risk Faktörleri.

\begin{abstract}
Objective: In the present study, we aimed to determine the frequency of chronic total occlusion and its relationship with cardiovascular risk factors in inpatients with acute coronary syndrome treated in our clinic.

Materials and methods: Patients who underwent coronary angiographic evaluation for acute coronary syndrome between April 2015 and September 2018 were included in the study. Patients with TIMI 0 flow in the lesion region were accepted as chronic total occlusion in coronary angiographic examinations. Risk factors were determined according to the anamnesis and laboratory findings.
\end{abstract}

Results: 904 patients were included in the study. Two hundred and fourteen patients (23\%) had CTO. Mean age (67 $\pm 11,60 \pm 13, \mathrm{p}<0.001)$, hypertension $(54.7 \%, 43.0 \%, \mathrm{p}=0.004)$ and diabetes mellitus $(41.1 \%, 31.6 \%, \mathrm{p}=0.013)$ were significantly higher in patients with CTO and male gender $(64 \%, 73 \%, \mathrm{p}=0.008)$, premature coronary artery disease $(10.3 \%, 19.9 \%, \mathrm{p}=0.001)$ and cigarette smoking $(28.0 \%, 48.8 \%, \mathrm{p}<0.001)$ were lower.

Conclusion: In the present study, there were significant differences in risk factors among patients with and without chronic total occlusion in acute coronary syndrome patients. To the best of our knowledge, this is the first study in the literature to demonstrate the relationship between chronic total occlusion and cardiovascular risk factors.

Keywords: Acute Coronary Syndrome, Chronic Total Occlusion, Cardiovascular Risk Factors.

\section{Giris}

Koroner arter hastalıkları dünyada ve ülkemizde önde gelen ölüm sebebidir. Bu ölümlerin önemli bir bölümü akut koroner sendromlar sebebiyle olmaktadir. Son yıllarda teşhis ve tedavide önemli gelişmeler olmuş, özellikle koroner anjiyografinin yaygınlaşması ve bu konudaki tecrübelerin artmasıyla ölüm oranlarında belirgin azalma olmuştur. Özellikle ST elevasyonlu miyokard infarktüsü (STEMI) tedavisinde primer perkütan koroner girişim kılavuzlarda Klas IA endikasyon önerisi ile yer almaktadır. Diğer yandan ST elevasyonsuz miyokard infarktüsünde (NSTEMI) 
kılavuzlar özellikle yüksek riskli hastalarda erken koroner anjiyografik değerlendirme önermektedir. Akut koroner sendromun diğer bir alt grubu olan anstabil anjina pektorisli (AAP) hastalara da koroner anjiyografi ünitesi olan birçok merkezde olduğu gibi kliniğimizde de erken koroner anjiyografi yapılmaktadır. Kronik total oklüzyon (KTO); koroner arterlerin 3 aydan daha uzun süreli tam tıkanıklığını ifade eder. Anjiyografik olarak lezyon bölgesinde TIMI 0 akım ile karakterizedir. Lezyonlar kalsiyum ve fibröz dokudan zengindir. Bu yüzden perkütan koroner girişim açısından zor lezyonlardır. Rutin anjiyografik uygulamaların yaklaşık $\%$ 15-30'unda tespit edilirler [1]. Koroner anjiyografide kronik total oklüzyon varlığı erken ve geç dönem kötü prognoz ile ilişkilidir [2,3]. Bu çalışmada kliniğimizde akut koroner sendrom tanısiyla tedavi edilen hastalarda kronik total oklüzyon sıklığı ve bunun kardiyovasküler risk faktörleriyle ilişkisini araştırdık.

\section{Gereç ve Yöntem}

2.1.Etik bildirimi: Çalışma retrospektif olarak dizayn edildi ve üniversitemiz girişimsel olmayan etik kurulunun onayı alınarak Helsinki Deklarasyonunda belirtilen esaslara göre gerçekleştirildi. Çalışmaya Nisan 2015-Eylül 2018 tarihleri arasında akut koroner sendrom sebebiyle kliniğimizde yatarak tedavi edilen hastalar dahil edildi.

2.2.Hasta seçimi: Hastalar anamnez, EKG bulguları ve Troponin I değerlerine göre ST elevasyonlu miyokard infarktüsü, ST elevasyonsuz miyokard infarktüsü ve anstabil anjina pektoris gruplarından birine dahil edildi. Anstabil anjina pektoris ve ST elevasyonsuz miyokard infarktüsü ayrımı Troponin I seviyelerine bakılarak yapıldı. Risk faktörleri anamnez ve başlangıç laboratuvar parametrelerine göre tespit edildi.

2.3.Tanı kriterleri: Yirmi dakikadan uzun süren tipik göğüs ağrısı olan, EKG'de komşu iki derivasyonda $\geq$ $1 \mathrm{mV}$ ST elevasyonu (V1, V2 veya V3'de $>0.2 \mathrm{mV}$ ) veya yeni gelişmiş sol dal bloğu olan ve Troponin I değeri yüksek olan hastalar STEMI olarak kabul edildi. Yirmi dakikadan uzun süren tipik gögüs ağrısıyla birlikte komşu iki derivasyonda horizontal $\geq 0.05 \mathrm{mV}$ ST depresyonu olan ve Troponin I seviyesi yüksek olan hastalar NSTEMI; aynı bulgularla Troponin I seviyesi normal olan hastalar AAP olarak kabul edildi. Koroner anjiyografik incelemelerde lezyon bölgesinde TIMI 0 akım olan hastalar KTO olarak kabul edildi. Her gün sigara kullanan hastalar adedine bakılmaksızın sigara içiyor kabul edildi [4]. Lipid düşürücü ilaç kullanan hastalar LDL seviyesine bakılmaksızın, ilaç kullanmayanlarda LDL > $130 \mathrm{mg} / \mathrm{dl}$ olanlar hiperlipidemik olarak sınıflandırıldı [5]. Birinci derece yakınlarında (erkeklerde $<55$ yaş, kadınlarda $<65$ yaş) miyokard infarktüsü veya ani ölüm öyküsü olanlar prematüre koroner arter hastalığı açısından riskli gruba dahil edildi. Antihipertansif ilaç kullananlar ve takiplerinde kan basıncı değerleri 2 veya daha fazla ölçümde yüksek tespit edilenler (nondiyabetiklerde > $140 / 90 \mathrm{~mm} \mathrm{Hg}$, diyabetiklerde > 130/80 mm Hg) hipertansif olarak kabul edildi [6]. Hastaneye yatışlarında oral antidiyabetik ilaç veya insülin kullananlar ile takiplerinde kan şekeri yüksek seyredenler (açlık kan şekeri > $140 \mathrm{mg} / \mathrm{dL}$, tokluk kan şekeri > $200 \mathrm{mg} / \mathrm{dL}$ ) diyabetes mellitusu (DM) olan hasta grubuna dahil edildi [7].

2.4.Dışlanma kriterleri: Dosya incelemesinde risk faktörlerinden herhangi birisi kayıt edilmemiş, kan örneklerinde eksiklik olan, kan örnekleri ya da detaylı anamnezi alınamadan exitus olan hastalarla koroner arter bypass operasyonu geçiren, kalp kapak hastalığı, kalp yetmezliği, kronik böbrek yetmezliği, kronik inflamatuar deri hastalığı, sistemik hastalığı olanlar çalışmaya dahil edilmedi.

2.5.Laboratuvar deneyleri ve görüntüleme yöntemleri: Tüm hastaların koroner anjiyografik görüntülemeleri General Electric Optima cihazı ile yapıldı. Biyokimyasal parametreler COBAS 411 Roche cihazı ile çalışıldı. Ekokardiyografik incelemeleri General Electric Vivid 7 cihazı ile yapıldı.

2.6.İstatistiksel analiz: Tüm analizler SPSS 21.0 İstatistik Paket Programı (SPSS Inc, Chicago, Illinois, ABD) kullanılarak yapıldı. Sürekli değişkenler; parametrik değişkenler için ortalama \pm standart sapma, parametrik olmayan değişkenler için medyan ve minimum-maksimum düzeyler olarak kaydedildi. Kategorik değişkenler sayı ve yüzde olarak temsil edildi. Dağılımın normalliğini değerlendirmek için Kolmogorov-Smirnov testi, homojenliğini değerlendirmek için Levene testi kullanıldı. Kategorik değişkenler ki-kare testi kullanılarak karşılaştırıldı. Kategorik olmayan değişkenlerde parametrik olanların karşılaştırılmasında student-T testi, parametrik olmayan değişkenlerin karşılaştırılmasında Mann-Whitney U testi kullanıldı.

\section{Bulgular}

Çalışmaya kriterlere uyan 904 hasta dahil edildi. Çalışmaya dahil edilen hastaların demografik özellikleri Tablo 1'de verilmiştir. İki yüz on dört hastada (\%23) KTO tespit edildi. KTO olan hastalarda ortalama yaş, hipertansiyon varlığ 1 ve diyabetes mellitus istatistiksel olarak daha yüksek saptandı (sırasıyla; $\mathrm{p}<0.001, \mathrm{p}=$ $0.004, p=0.013$ ), erkek cinsiyet, prematüre koroner arter hastalığı öyküsü, sigara kullanımı (sırasıyla; $p=$ $0.008, p=0.001, p<0.001)$ ise daha düşük saptand1. Hiperlipidemi varlığı KTO olan hasta grubunda daha düşüktü ancak bu istatistiksel olarak anlamlı değildi. Sol ventrikül ejeksiyon fraksiyonu KTO olan hastalarda daha düşük saptandı $(\mathrm{p}<0.001)$.

Laboratuvar bulguları incelendiğinde (Tablo2); KTO olan hastalarda serum glukoz, HgbA1c, kreatinin, hsCRP, NT-ProBNP ve fibrinojen düzeyleri istatistiksel olarak anlamlı şekilde yüksekti (sırasıyla; $\mathrm{p}<0.001$, $\mathrm{p}<$ $0.001, \mathrm{p}<0.001, \mathrm{p}<0.001, \mathrm{p}<0.001, \mathrm{p}=0.013)$, hemoglobin ve glomerüler filtrasyon hızı ise istatistiksel olarak anlamlı şekilde daha düşük saptandı (sırasıyla; $p$ $<0.001, \mathrm{p}<0.001$ ). Diğer parametreler arasında anlamlı bir fark yoktu. 
Tablo1. Kronik total oklüzyon varlığı / yokluğuna göre hastaların demografik özellikleri

\begin{tabular}{|l|l|l|l|}
\hline Değişkenler & $\begin{array}{l}\text { KTO(+) } \\
(\mathbf{n = 2 1 4 )}\end{array}$ & $\begin{array}{l}\text { KTO(-) } \\
(\mathbf{n = 6 9 0 )}\end{array}$ & $\begin{array}{l}\mathbf{P} \\
\text { değeri }\end{array}$ \\
\hline $\begin{array}{l}\text { Yaş } \\
\text { (ortalama } \text { (YS) }\end{array}$ & $67 \pm 11$ & $60 \pm 13$ & $<\mathbf{0 . 0 0 1}$ \\
\hline $\begin{array}{l}\text { Erkek cinsiyet n } \\
(\%)\end{array}$ & $136(64)$ & $507(73)$ & $\mathbf{0 . 0 0 8}$ \\
\hline Aile öyküsü, n(\%) & $22(10.3)$ & $137(19.9)$ & $\mathbf{0 . 0 0 1}$ \\
\hline $\begin{array}{l}\text { Hipertansiyon, n } \\
(\%)\end{array}$ & $117(54.7)$ & $298(43.0)$ & $\mathbf{0 . 0 0 4}$ \\
\hline $\begin{array}{l}\text { Diyabetes } \\
\text { mellitus, n (\%) }\end{array}$ & $88(41.1)$ & $218(31.6)$ & $\mathbf{0 . 0 1 3}$ \\
\hline $\begin{array}{l}\text { Hiperlipidemi, n } \\
(\%)\end{array}$ & $65(30.4)$ & $265(38.4)$ & 0.085 \\
\hline Sigara, n (\%) & $60(28.0)$ & $337(48.8)$ & $<\mathbf{0 . 0 0 1}$ \\
\hline $\begin{array}{l}\text { Sol ventrikül EF } \\
(\%)\end{array}$ & $44 \pm 9$ & $47 \pm 9$ & $<\mathbf{0 . 0 0 1}$ \\
\hline
\end{tabular}

Kisaltmalar: KTO, kronik total oklüzyon; EF, ejeksiyon fraksiyonu; KB, kan basıncı. $\mathrm{p}<0.05$ istatistiksel olarak anlamlı kabul edilmiştir.

Tablo2. Kronik total oklüzyon varlığı / yokluğuna göre laboratuvar değerleri

\begin{tabular}{|c|c|c|c|}
\hline Değişkenler & KTO (+) & KTO (-) & \begin{tabular}{|c|}
$\mathbf{P}$ \\
değeri
\end{tabular} \\
\hline $\operatorname{Hemoglobin}(\mathrm{g} / \mathrm{dL})$ & $13.3 \pm 1.9$ & $14.1 \pm 1.7$ & $<0.001$ \\
\hline $\begin{array}{l}\text { Beyaz hücre }\left(10^{3}\right. \\
/ \mu \mathrm{L})\end{array}$ & $10.9 \pm 3.6$ & $11.0 \pm 3.6$ & 0.657 \\
\hline $\begin{array}{l}\text { Trombosit } \\
/ \mu \mathrm{L})\end{array}$ & $236 \pm 75$ & $239 \pm 72$ & 0.590 \\
\hline $\begin{array}{l}\text { Serum } \\
\text { glukoz(mg/dL) }\end{array}$ & $159 \pm 83$ & $140 \pm 74$ & $<0.001$ \\
\hline HgbA1c(\%) & $7.1 \pm 2.7$ & $6.2 \pm 2.7$ & $<0.001$ \\
\hline \begin{tabular}{|l|l|}
$\begin{array}{l}\text { Kreatinin } \\
\text { dL) }\end{array}$ & $(\mathrm{mg} \quad$ \\
\end{tabular} & $1.21 \pm 0.3$ & $1.07 \pm 0.3$ & $<0.001$ \\
\hline eGFR (mL / dk) & $59 \pm 19$ & $73 \pm 19$ & $<0.001$ \\
\hline $\begin{array}{l}\text { Total kolesterol } \\
(\mathrm{mg} / \mathrm{dL})\end{array}$ & $187 \pm 55$ & $191 \pm 55$ & 0.332 \\
\hline $\begin{array}{l}\text { Trigliserit (mg } \\
\text { dL) }\end{array}$ & $\begin{array}{c}178(32- \\
1161)\end{array}$ & 165 (39-923) & 0.931 \\
\hline $\begin{array}{l}\text { LDL kolesterol } \\
(\mathrm{mg} / \mathrm{dL})\end{array}$ & $115.63 \pm 43$ & $120.77 \pm 43$ & 0.142 \\
\hline $\begin{array}{l}\text { HDL kolesterol } \\
(\mathrm{mg} / \mathrm{dL})\end{array}$ & $39.9 \pm 9.7$ & $40.1 \pm 11.3$ & 0.818 \\
\hline Hs-CRP (mg / dL) & $7.4 \pm 3.8$ & $6.3 \pm 3.9$ & 0.001 \\
\hline \begin{tabular}{|l|} 
NT-ProBNP (pg \\
mL)
\end{tabular} & $\begin{array}{c}2813(29- \\
11827) \\
\end{array}$ & $\begin{array}{c}1433(5- \\
11345)\end{array}$ & $<0.001$ \\
\hline $\begin{array}{l}\text { Homosistein (nmol } \\
/ \mathrm{mL})\end{array}$ & $19.7 \pm 13.5$ & $17.7 \pm 10.2$ & 0.087 \\
\hline $\begin{array}{l}\text { Fibrinojen (mg / } \\
\text { dL) }\end{array}$ & $435 \pm 149$ & $397 \pm 123$ & 0.013 \\
\hline
\end{tabular}

Kisaltmalar: KTO, kronik total oklüzyon; HgbA1c, hemoglobin A1c; eGFR, glomerüler filtrasyon hızı; HsCRP, yüksek duyarlıklı C-reaktif protein; NT-ProBNP, $\mathrm{N}$ terminal beyin natriüretik peptid. $\mathrm{p}<0.05$ istatistiksel olarak anlamlı kabul edilmiştir.
KTO sıklığının akut koroner sendrom türlerine göre dağılımına bakıldığında (Tablo 3) KTO olan hastalarda olmayanlara göre NSTEMİ görülme sıklığının anlamlı şekilde yüksek ( $p<0.001)$, STEMİ görülme sıklığının anlamlı şekilde düşük olduğu $(\mathrm{p}<0.001)$ tespit edildi. AAP sıklığı açısından her iki grup arasında fark olmadığı görüldü $(\mathrm{p}=0,945)$.

Tablo3.Kronik total oklüzyon sıklığının ve akut koroner sendrom tiplerine göre dağılımı

\begin{tabular}{|l|c|c|c|}
\hline & KTO (+) & KTO (-) & P değeri \\
\hline STEMİ n (\%) & $78(36)$ & $485(70)$ & $<\mathbf{0 . 0 0 1}$ \\
\hline NSTEMİ n (\%) & $123(58)$ & $157(23)$ & $<\mathbf{0 . 0 0 1}$ \\
\hline AAP n (\%) & $13(6)$ & $48(7)$ & 0.945 \\
\hline
\end{tabular}

infarktüsü; NSTEMI, ST elevasyonsuz miyokard infarktüsü; AAP, anstabil anjina pektoris; KTO, kronik total oklüzyon.

\section{Tartışma}

Bu çalışmada; akut koroner sendromlu hastalarda KTO sıklığı, rutin anjiyografik uygulamalarda tespit edilen oranlara ( 1 ) benzer olarak \% 23 olarak bulundu. KTO'su olan ve olmayan hasta grupları arasında risk faktörleri açısından anlamlı farklar olduğu tespit edildi. KTO olan hastalarda ortalama yaş, hipertansiyon ve DM sıklığı olmayanlara göre daha fazlayd1. Erkek cinsiyet oranı, prematüre koroner arter hastalığı öyküsü ve sigara kullanımı daha düşük tespit edildi. Hiperlipidemi açısından iki grup arasında anlamlı fark izlenmedi. Laboratuvar bulguları incelendiğinde; KTO grubunda serum glukoz, HgbA1c, kreatinin, Hs-CRP, NTProBNP ve fibrinojen seviyeleri daha yüksek, hemoglobin ve glomerüler filtrasyon hızı ise daha düşük tespit edildi.

KTO'nun aterosklerozun geç dönemlerini temsil etmesi sebebiyle; aterosklerozun yıllar içerisinde ilerleyici özelliği, yaşlanmanın bir parçası olması ve risk faktörlerine maruz kalma süresinin uzaması KTO hastalarının daha yaşı kişiler olması ile ilişkilendirilebilir [8]. Artmış arteryel kan basıncı değerlerinin artmış aterosklerotik risk ile birlikte olduğu [9] ve hipertansiyonun birkaç mekanizma ile ateroskleroza yol açtığı düşünülmektedir. Bunlardan bazılar1; makaslama etkisi (shear stres), trombosit ve fibrin mikrotrombüsleri oluşturması ve aterojenik hiperlipoproteinemiye sebep olmasidir [10]. Bu çalışmada hipertansiyon varlığı KTO grubunda yüksek tespit edilmiştir ve lezyon morfolojisinde kronik total oklüzyon oluşumuna eğilimi artırdığını düşündürmektedir. Diyabetes mellitus ateroskleroz için majör risk faktörlerinden birisidir ve diyabetik hastalarda ateroskleroz daha yaygın ve komplike olma eğilimindedir. Diyabet daha çok mikrovasküler düzeyde hastalık yapsa da aşikar diyabet gelişmeden önceki dönemde insülin rezistansına bağlı erken dönemde büyük damarlarda ateroskleroz başlamaktadır. Bu yüzden diyabetik hastalarda ilk tanı konduğunda lezyonların kompleks ve yaygın olduğu 
düşünülmektedir. Ayrıca yapılan başka bir çalışmada hiperglisemi iyi kontrol edilse bile aterosklerotik plaklarda kalsiyum içeriğinin gittikçe artış gösterdiği tespit edilmiştir [11]. KTO olan hastalarda DM oranının yüksek saptanması bu bilgilerle uyumludur.

KTO’da erkek cinsiyet oranını düşük tespit ettik. Her ne kadar kadınlar ateroskleroz açısından menopoza kadar avantajlı iseler de 50 yaş sonrası ateroskleroz erkeklere göre daha hızlı ilerleyip cinsiyet açısından dezavantaja dönüşebilmektedir. Celermajer ve ark. yaptıkları çalışmada 50 yaş sonrası bayanlarda endotelyal disfonksiyonun yıllar içinde erkeklere oranla 2 kattan fazla bir hızla arttığını göstermişlerdir [12]. KTO‘nun ileri yaşta ve aterosklerozun geç döneminde ortaya çıkması bu durumu açıklayabilir. Bu çalışmada KTO olanlarda sigara kullanma oranı anlamlı olarak düşük tespit edildi. Sigara kullanımının; endotelyal disfonksiyon ve hasara sebep olarak aterosklerozu başlatmasının yanısıra; proaterojenik lipitlerin oksidasyonuna yol açması, yüksek dansiteli lipoproteinlerin seviyesini düşürmesi, inflamasyonu tetiklemesi ve prokoagülan etkiler yapması gibi başka olumsuz etkileri de vardır [13]. Özellikle trombojenik etkisi sebebiyle akut koroner olaylar sigara kullananlarda daha genç yaşlarda ortaya çıkmaktadır.

KTO'nun ise daha kronik ve sessiz bir gidiş göstermesi ve ileri yaşlarda ortaya çıkması, KTO olan grupta olmayanlara göre sigara kullanımının düşük çıkmasını açıklayabilir. Yine prematüre koroner arter hastalığ öyküsünün KTO grubunda düşük tespit edilişi sigara kullanımındaki benzer sebeplerle (erken yaşta koroner olay yaşama, lezyonların hızlı gelişmesi vb.) [14] ortaya çıkmış olabilir.

Çalışmamızda KTO olan ve olmayanlar arasında hiperlipidemi açısından anlamlı bir fark tespit edilmedi. Yine aynı şekilde kolesterol, trigliserit, HDL ve LDL değerlerinde anlamlı bir fark yoktu. Her ne kadar KTO lezyonlarının lipitten fakir oldukları kabul edilse de Srivatsa ve ark. yaptıkları otopsi çalışmalarında lezyon yaşı genç KTO'ların lipitten zengin iken ilerleyen zamanlarda bu lezyonların daha sikı ve fibrokalsifik hale geldiğini göstermişlerdir $[15,16]$.

Çalışmamızın kısıtlılıkları; KTO vakalarının AKS ile başvuran hastalar arasından seçilmiş olması, KTO olarak kabul edilen lezyonların gerçekte ne kadarının KTO ne kadarının akut lezyonların tam tıkanıklığı olduğu konusunda küçük de olsa bir kısıtlılık ortaya çıkartmaktadır. Çünkü AKS ile basvuran ve koroner anjiografisinde \%100 tıkalı olarak saptanan damarları KTO olarak sınıflandırmak her zaman doğru olmayabilir. Girisimsel tedavi ile başarılı olunamayan hastaların küçük bir kısmında AKS'dan sorumlu olabilecek damardan tel ya da balon ile geçilememesi bu damarların yanlışlıkla KTO olarak sınıflandırılmasına neden olabilmektedir. Bazen de NSTMI hastalarında AKS ile ilişkisi olmayan lezyonların AKS dan sorumlu lezyon olduğu varsayılarak asıl sorumlu lezyon KTO olarak kabul edilebilebilmektedir.

\section{Sonuç}

Ateroskleroz birçok faktörün iştirak ettiği oldukça kompleks bir patolojik süreci ifade eder. Lezyon morfolojileri yağlı çizgilenmeler gibi başlangıç lezyonlarından oldukça komplike plaklara kadar uzanan geniş bir spektrumu içine alır. Risk faktörlerinin ateroskleroz ve koroner arter hastalıklarının ortaya çıkmasında etkili oldukları bilinse de hangi risk faktörünün ne tür lezyonlara yol açabileceği tam anlamıyla ortaya konabilmiş değildir. Bildiğimiz kadarıyla bu çalışma akut koroner sendromlu hastalarda aterosklerotik koroner arter hastalığının kompleks ve geç bir dönemini ifade eden kronik total oklüzyon sıklığı ile risk faktörleri ilişkisini ortaya koyan literatürdeki ilk çalışmadır.

\section{Kaynaklar}

1. Kahn JK, Angiographic suitability for catheter revascularization of total coronary occlusions in patients from a community hospital setting. American heart journal 1993, 126:561-564

2. Tajstra M, Gasior $\mathbf{M}$ ve ark. Comparison of five-year outcomes of patients with and without chronic total occlusion of noninfarct coronary artery after primary coronary intervention for ST-segment elevation acute myocardial infarction. The American journal of cardiology 2012, 109:208-213.

3. Gierlotka $\mathbf{M}$, Tajstra $\mathbf{M}$ ve ark. Impact of chronic total occlusion artery on 12-month mortality in patients with nonST-segment elevation myocardial infarction treated by percutaneous coronary intervention (from the PL-ACS Registry). International journal of cardiology 2013, 168:250 254.

4. Delp MD, Behnke BJ ve ark. Ageing diminishes endothelium-dependent vasodilatation and tetrahydrobiopterin content in rat skeletal muscle arterioles. The Journal of physiology 2008, 586:1161-1168.

5. MacMahon S, Peto $\mathrm{R}$ ve ark. Blood pressure, stroke, and coronary heart disease: part 1, prolonged differences in blood pressure: prospective observational studies corrected for the regression dilution bias. The Lancet 1990, 335:765-774

6. Grundy SM, Becker D ve ark. Detection, evaluation, and treatment of high blood cholesterol in adults (Adult Treatment Panel III). Circulation 2002, 106:3143-3421.

7. Stabley JN, Towler DA. Arterial calcification in diabetes mellitus: preclinical models and translational implications. Arteriosclerosis, thrombosis, and vascular biology. 2017;37(2):205-17

8. Celermajer DS, Sorensen KE ve ark. Aging is associated with endothelial dysfunction in healthy men years before the agerelated decline in women. Journal of the American College of Cardiology 1994, 24:471-476.

9. Messner B, Bernhard D: Smoking and Cardiovascular DiseaseSignificance: Mechanisms of Endothelial Dysfunction and Early Atherogenesis. Arteriosclerosis, thrombosis, and vascular biology 2014, 34:509-515.

10. Yusuf S, Hawken $S$ ve ark. Effect of potentially modifiable risk factors associated with myocardial infarction in 52 countries (the INTERHEART study): case-control study. The lancet 2004, 364:937-952

11. Srivatsa SS, Edwards WD ve ark. Histologic correlates of angiographic chronic total coronary artery occlusions: influence of occlusion duration on neovascular channel patterns and intimal plaque composition. Journal of the American College of Cardiology 1997, 29:955-963.

12. Suzuki T, Hosokawa $H$ ve ark. Time-dependent morphologic characteristics in angiographic chronic total coronary 
occlusions. American Journal of Cardiology 2001, 88:167169.

http://edergi.cbu.edu.tr/ojs/index.php/cbusbed isimli yazarın CBU-SBED başlıklı eseri bu

Creative Commons Alınt1-Gayriticari4.0

Uluslararası Lisansı ile lisanslanmıştır.

(c) (i) (2) 